Artigo/Article

\title{
Avaliação eletroforética, cromatográfica e molecular da Hb D Los Angeles no Brasil
}

Electrophoretical, chromatographic and molecular valuations of H b D Los Angeles in Brazil

Ana R. Chinelato-Fernandes ${ }^{1}$ Guilherme G. Leoneli Patrícia O. Calderan ${ }^{3}$ Rute Blasi de Oliveira ${ }^{4}$ Wilson Araújo da Silva Jr. ${ }^{5}$ Claudia Augusta Hidalgo ${ }^{6}$ Claudia Regina Bonini-Domingos ${ }^{7}$

\begin{abstract}
A variante de hemoglobina $(\mathrm{Hb}) \mathrm{D}$ mais comum, $\mathrm{Hb} \mathrm{D}$ Los Angeles ou $D$ Punjab, é originada de uma tran sversão GAA $\rightarrow$ CAA no códon 121 da globina beta; essa mutação resulta na substituição do ácido glutâmico por glutamina na proténa. É a terceira variante de hemoglobina mais freqüente da população brasileira. Como as hemoglobinas D apresentam migração similar à hemoglobina $\mathrm{S}$ em pH alcalino, e com a hemoglobina A em pH ácido, são necessários vários testes para o correto diagnóstico. No presente estudo objetivou-se relacionar os diferentes procedimentos laboratoriais de rotina diagnóstica, além da análise molecular, para estabelecer o perfil de Hb D Los Angeles no Brasil. Foram analisados 47 indivíduos da população brasileira com provável $\mathrm{Hb}$ D Los Angeles, por vários procedimentos eletroforéticos em diferentes condicões de pH, além da cromatografia líquida de alta pressão, etestes moleculares para confirmação da mutação. Foram encontrados quatro tipos de combinações de hemoglobinas: 42 indivíduos portadores dehemoglobina $A D$ Los Angeles, dois indivíduos com doença de $\mathrm{Hb}$ S/D Los Angeles, dois indivíduos com $\mathrm{Hb} D$ Los Angeles e talassemia beta e um indivídu o com $\mathrm{Hb} \mathrm{D}$ Los Angeles e $\mathrm{Hb}$ Lepore. Os indivíduos heterozigotos para D Los Angeles são assintomáticos, entretanto, em associação com outras variantes etalassemias podem apresentar graus variáveis de manifestações clínicas. Os resultados apresentados enfatizaram a necessidade da associação de várias metodologias para a identificação da Hb D Los Angeles, além de auxiliar na elucidação de combinações raras. Rev. bras. hematol. hemoter. 2003:25(3):161-168.
\end{abstract}

Palavras-chave: Hemoglobina D Los Angeles; diagnóstico laboratorial; hemoglobinopatias.

${ }^{1}$ Laboratório de Hemoglobinas e Genética das Doenças Hematológicas. Mestre em Genética pelo programa de Pós-Graduação do In stituto de Biociências, Letras e Ciências Exatas, Unesp - São José do Rio Preto-SP.

${ }^{2}$ Mestre em Genética pelo programa de Pós-Graduação do Instituto de Biociências, Letras e Ciências Exatas - Un esp, São José do Rio Preto-SP.

${ }^{3}$ Farmacêutica Bioquímica, responsável pelo Laboratório de Hematologia da Faculdade de Farmácia - Unic, Cuiabá-MT. 'Bioquímica do Laboratório de Hematologia do Centro de Hematologia e Hemoterapia de Santa Catarina - Fundação de Apoio ao Hemosc e Cepon - Fahece.

${ }^{5}$ Professor Doutor colaborador do Hemocentro de Ribeirão Preto-SP.

${ }^{6}$ Mestre em Matemática Aplicada pelo Instituto de Biociências, Letras e Ciências Exatas - Unesp, São José do Rio Preto-SP.

7 Professora Doutora responsável pelo Laboratório de Hemoglobinas e Genética das Doenças Hematológicas do

Instituto de Biociências, Letras e Ciên cias Exatas - Unesp, São José do Rio Preto-SP.

Trabalho desenvolvido no Laboratório de Hemoglobinas e Genética das Doenças Hematológicas - Unesp

Correspondência para: Ana Regina Chinelato Fernandes

Ibilce - Unesp - Rua Cristóvão Colombo, 2265 - 15054-000 - São José do Rio Preto-SP

Fone: (17) 2212392 - E-mail: ar.chinelato@uol.com.br 


\section{Introdução}

As variantes de hemoglobinas foram estudadas extensivamente nos últimos anos. A hemoglobina D (Hb D) foi descoberta em 1951 por Itano e é a terceira variante de hemoglobina mais comum depois das hemoglobinas $\mathrm{Hb} \mathrm{S}$ e Hb C. ${ }^{1,2,3}$ A Hb D apresenta mobilidade eletroforética similar à $\mathrm{Hb} \mathrm{S}$ em pH alcalino e na posição da Hb A em gel de ágar em pH ácido.

A Hb D Los Angeles, também conhecida como D Punjab, é a mais comum das hemoglobinas D, sendo originada da transversão GAA $\rightarrow$ CAA no códon 121, (éxon 3) do gene da globina beta. Essa mutação resulta na troca do ácido glutâmico por glutamina durante o processo de tradução. ${ }^{4}$ Essa hemoglobina é descrita tanto em heterozigose como em homozigose, além da combinação com Hb S ou talassemias alfa ou beta. Os indivíduos heterozigotos e homozigotos são assintomáticos, enquanto os que apresentam associação com $\mathrm{Hb}$ S ou talassemia beta podem desenvolver anemia hemolítica de discreta a moderada. ${ }^{5}$

Apesar de ser possível a diferenciação pelos métodos eletroforéticos descritos acima, tais metodologias possuem limitações, uma vez que algumas variantes apresentam comportamento eletroforético similar, por possuir propriedades bioquímicas e/ou funcionais muito semelhantes, como é o caso das hemoglobinas $\mathrm{D}$ e $\mathrm{S}$ em $\mathrm{pH}$ alcalino. ${ }^{2,3,4,6,7}$ Desse modo, além da eletroforese alcalina, são necessários testes confirmatórios para o correto diagnóstico, como eletroforese ácida, cromatografia líquida de alta pressão (HPLC), focalização isoelétrica (IEF), eletroforese de cadeias globínicas e a utilização de técnicas de biologia molecular, como a reação em cadeia da polimerase (PCR), análise dos fragmentos de restrição de diferentes tamanhos (RFLP) e seqüenciamento. ${ }^{8}$

No presente estudo objetivou-se relacionar os diferentes procedimentos laboratoriais de rotina diagnóstica, além da análise molecular, para estabelecer o perfil de Hb D Los Angeles no Brasil.

\section{Material e Métodos}

Foram analisadas 47 amostras de sangue periférico, sendo 19 provenientes de indivíduos do sexo masculino e 28 do sexo feminino, com idades que variaram de recém-nascidos até 58 anos. Essas amostras, provenientes de sete estados do Brasil
- RS, SC, SP, RJ, MT, MS e SE, foram enviadas ao Laboratório de Hemoglobinas e Genética das Doenças Hematológicas - Unesp. O sangue foi coletado em frasco estéril com anticoagulante EDTA a $5 \%$, após consentimento informado. Para a determinação dessa variante, foram realizados testes de triagem, que consistiram de: resistência globular osmótica em $\mathrm{NaCl}$ a $0,36 \%, 9$ análise da morfologia eritrocitária a fresco ${ }^{10}$ e eletroforese alcalina em acetato de celulose utilizando-se tampão TrisEDTA-borato em pH 8,5. ${ }^{11}$ Como procedimento de confirmação, foram realizadas as eletroforeses em ágar com tampão fosfato $\mathrm{pH}$ 6,2; ${ }^{12}$ de cadeias globínicas em acetato de celulose com tampão TrisEDTA-borato, uréia e mercaptoetanol $;{ }^{13}$ focalização isoelétrica em agarose ${ }^{14}$ e cromatografia líquida de alta pressão (HPLC), com o equipamento Variant, da Bio-Rad, utilizando-se o kit de diagnóstico para talassemia beta heterozigota.

Para as análises moleculares, o DNA foi obtido dos glóbulos brancos através do método de extração fenólica, ${ }^{15}$ e o éxon 3 da globina beta foi amplificado através da reação em cadeia da polimerase.${ }^{16}$ A seqüência de primers utilizada na reação de amplificação foi: Primer sense - CD1 5 TGC CTC TTT GCA TTC TA 3' e Primer anti-sense - CD2 5’TAG AAT GGT GCA AAG AGG CA 3’. Do produto amplificado, cinco microlitros foram digeridos com a endonuclease de restrição EcoRI por duas horas e trinta minutos e o produto da digestão submetido à eletroforese em gel de poliacrilamida para observação das bandas mutantes e/ou normais. O códon 121 apresenta um sítio de digestão para a enzima EcoRI no alelo normal, que é excluído no mutante D Los Angeles, permitindo a análise por PCR-RFLP. A digestão do alelo normal gera produtos de $296 \mathrm{pb}$ e $268 \mathrm{pb}$ enquanto o alelo mutante apresenta uma única banda de $564 \mathrm{pb}$. Os casos duvidosos foram submetidos a reação de seqüenciamento. ${ }^{17} \mathrm{Na}$ presença de associação com outras variantes ou talassemias, foram realizados testes moleculares por PCR-ASO, com kits $\mathrm{mD}_{\mathrm{x}}$ da Bio-Rad para confirmação.

\section{Resultados}

Os resultados obtidos nos procedimentos de triagem dos indivíduos investigados com suspeita de serem portadores de hemoglobina D Los Angeles estão relacionados na tabela 1. Observaram-se $80 \%$ dos indivíduos avaliados com resis- 
Tabela 1

Resultados obtidos dos procedimentos de triagem dos indivíduos com suspeita de serem portadores de $\mathrm{Hb}$ D Los Angeles

\begin{tabular}{cccc}
\hline Código & $\begin{array}{c}\text { Resistência } \\
\text { Osmótica }\end{array}$ & $\begin{array}{c}\text { Morfologia } \\
\text { Eritrocitária* }^{*}\end{array}$ & $\begin{array}{c}\text { Eletroforese } \\
\text { Alcalina }\end{array}$ \\
\hline AR-010 & Negativo & $\mathrm{N} /+$ & AS
\end{tabular}

$\begin{array}{lll}\text { AR-031 Negativo } & \mathrm{N} /+ & \text { AS }\end{array}$

AR-033 Negativo ++ AS

$\begin{array}{lll}\text { AR-035 Negativo } & \mathrm{N} /+ & \text { AS }\end{array}$

AR-037 Positivo $\mathrm{N} /+$ AS

AR-040 Negativo $\mathrm{N} /+$ AS

$\begin{array}{lll}\text { AR-060 Negativo } & \mathrm{N} /+ & \mathrm{ASH}\end{array}$

AR-121 Negativo + AS

$\begin{array}{lll}\text { AR-130 Negativo } & \mathrm{N} /+ & \text { ASH }\end{array}$

AR-131 Positivo ++ SS

$\begin{array}{llll}\text { AR-134 -- } & -- & \text { AS }\end{array}$

$\begin{array}{llll}\text { AR-135 Positivo } & \mathrm{N} /+ & \text { ASH }\end{array}$

$\begin{array}{lll}\text { AR-136 Positivo } & \mathrm{N} /+ & \text { AFS }\end{array}$

AR-137 Positivo $++\quad$ ASH

AR-156 Negativo

AR-163 Negativo

AR-171 Negativo

AR-180 Negativo

AR-196 Negativo

AR-199 Positivo

AR-200 Negativo

AR-201 Negativo

AR-208 Positivo

AR-209 Negativo

AR-212 Negativo

AR-213 Negativo

AR-216 Negativo

AR-217 Negativo

AR-218 Negativo

AR-219 Negativo

AR-221 Negativo

AR-234 Positivo

AR-236 Positivo

AR-237 Negativo

AR-238 Negativo

AR-239 Negativo

AR-240 Negativo

G-005 Negativo

G-006 Negativo

G-032 Negativo

G-034 Negativo

G-035 Negativo

G-036 Negativo

G-103 Negativo

G-104 Negativo

G-107 Negativo

G-108

--

$++\quad S S$

$\mathrm{N} /+\quad$ AS

$\mathrm{N} /+\quad$ AS

$+\quad$ AS

$\mathrm{N} /+\quad$ AS

$+/++\quad$ SS

$\mathrm{N} /+\quad$ ASH

$\mathrm{N}+\mathrm{ASH}$

$\begin{array}{ll}\mathrm{N} /+ & \text { ASH } \\ +/++ & \text { SSF }\end{array}$

$\mathrm{N} /+\quad$ AS

$\mathrm{N} /+\quad$ AFSH

$\mathrm{N} /+\quad$ AS

$\mathrm{N} /+\quad$ AS

$\begin{array}{ll}\mathrm{N} /+ & \text { AS } \\ \mathrm{N} /+ & \text { AS } \\ \mathrm{N} /+ & \text { AS }\end{array}$

$\begin{array}{ll}\mathrm{N} /+ & \text { AS } \\ \mathrm{N} /+ & \text { AS }\end{array}$

$+\quad$ ASH

++ AS

$++\quad$ ASH

$\begin{array}{cc}\mathrm{N} /+ & \text { AS } \\ + & \text { ASH }\end{array}$

$\begin{array}{ll}+ & \text { ASH } \\ + & \text { ASH }\end{array}$

$+/++$ ASF

$\mathrm{N} /+\quad A S$

$\begin{array}{ll}\mathrm{N} /+ & \text { AS } \\ + & \text { ASH }\end{array}$

$\mathrm{N} /+\quad$ AS

$\mathrm{N} /+\quad$ AS

$+/++\quad$ AS

$\mathrm{N} /+\quad$ AS

$\begin{array}{ll}\mathrm{N}+ & \text { AS } \\ + & \text { AS }\end{array}$

AS

- Nã foi possiv $(N)$, com alterações discretas $(+)$, alterações moderadas $(++)$, alterações acentuadas $(+++)$ e intermediárias $(\mathrm{N} /+),(+1$ $++),(+++++)$. tência osmótica em $\mathrm{NaCl}$ 0,36\% negativa. Alterações discretas quanto à morfologia eritrocitária foram descritas na maioria dos indivíduos. O perfil eletroforético dos heterozigotos, com uma fração hemoglobínica na posição de $\mathrm{Hb}$ A e outra semelhante à $\mathrm{Hb} \mathrm{S}$, foi encontrado na maior parte dos casos, com exceção de cinco amostras, que apresentaram perfil homozigoto para $\mathrm{Hb} \mathrm{S}$; três amostras com presença de $\mathrm{Hb} \mathrm{F}$ e uma amostra com padrão homozigoto para $\mathrm{Hb} S$ além da presença de $\mathrm{Hb}$ F. A presença de $\mathrm{Hb} F$ e valores baixos de $\mathrm{Hb} \mathrm{A}$ e da fração semelhante à $\mathrm{Hb} \mathrm{S}$ na amostra AR-136 já era esperada por se tratar de um recém-nascido.

Alguns indivíduos, apesar de adultos também apresentaram frações na posição de Hb F. As doze amostras com presença de $\mathrm{Hb} \mathrm{H}$ em eletroforese alcalina foram investigadas por metodologias específicas, apresentando resultados negativos para talassemia alfa. Em algumas amostras não foi possível a realização dos testes de resistência osmótica e morfologia eritrocitária devido à pequena quantidade de material enviado.

Nas análises eletroforéticas em pH ácido, a maioria das amostras apresentou perfil eletroforético de $\mathrm{Hb} \mathrm{AA}$, sugerindo variante do tipo D. Cinco amostras apresentaram uma fração na faixa de $\mathrm{Hb} \mathrm{F}$, e duas amostras o padrão de "doença de $\mathrm{Hb}$ S/D”, ou seja, perfil homozigoto para $\mathrm{Hb} \mathrm{S}$ em $\mathrm{pH}$ alcalino e do heterozigoto AS em pH ácido.

$\mathrm{Na}$ tabela 2 estão apresentados os resultados obtidos nas eletroforeses alcalina, ácida e de cadeias globínicas em $\mathrm{pH}$ alcalino. Todas as amostras analisadas apresentaram perfil eletroforético similar à Hb D em pH alcalino e ácido, e confirmadas como mutantes de cadeia beta pelo procedimento específico de análise de cadeias globínicas. Inúmeras variantes apresentam o padrão de migração similar às hemoglobinas do tipo D; entretanto, muitas são mutantes de cadeia alfa. Desse modo, a utilização da eletroforese de cadeias globínicas foi necessária para a identificação dessas variantes como do tipo D. É possível diferenciar a $\mathrm{Hb} \mathrm{G}$ Philadelphia, que é um mutante de cadeia alfa da Hb Korle-Bu, mutante de cadeia beta. Ainda assim, não seria possível a identificação entre $\mathrm{Hb} \mathrm{D}$-Los Angeles e Hb Korle-Bu, pois as duas variantes apresentam as frações mutantes com o mesmo padrão de migração.

Na tabela 3 encontram-se os dados da análise por HPLC com o kit de diagnóstico para talas- 
Tabela 3

\begin{tabular}{|c|c|c|c|c|c|c|c|c|c|c|c|c|c|c|c|c|c|c|c|c|c|c|}
\hline \multirow[b]{2}{*}{ Cod. } & \multicolumn{2}{|c|}{ Desc. $1^{*}$} & \multicolumn{2}{|c|}{$F$} & \multicolumn{2}{|c|}{ P2 } & \multicolumn{2}{|c|}{ P3 } & \multicolumn{2}{|c|}{ A0 } & \multicolumn{2}{|c|}{ A2 } & \multicolumn{2}{|c|}{ s } & \multicolumn{2}{|c|}{ D } & \multicolumn{2}{|c|}{ c } & \multicolumn{2}{|c|}{ Desc. $2^{\star}$} & \multicolumn{2}{|c|}{ Desc. $3^{*}$} \\
\hline & $\%$ & TR & $\%$ & TR & $\%$ & TR & $\%$ & TR & $\%$ & TR & $\%$ & TR & $\%$ & TR & $\%$ & TR & $\%$ & TR & $\%$ & TR & $\%$ & TR \\
\hline AR-010 & & & & & 6,70 & 1,30 & 3,70 & 1,70 & 74,40 & 2,40 & 2,40 & 3,64 & & & 13,10 & 4,18 & & & & & & \\
\hline AR-031 & 2,80 & 2,10 & 0,70 & 1,10 & 3,90 & 1,30 & 3,40 & 1,70 & 50,00 & 2,60 & 2,20 & 3,64 & & & 36,70 & 4,28 & & & & & & \\
\hline AR-033 & & & & & 4,20 & 1,30 & 4,50 & 1,70 & 55,20 & 2,40 & 1,00 & 3,67 & & & 35,30 & 4,17 & & & & & & \\
\hline AR-035 & & & 0,80 & 1,10 & 3,20 & 1,30 & 4,40 & 1,70 & 54,90 & 2,40 & 1,10 & 3,68 & & & 35,70 & 4,18 & & & & & & \\
\hline AR-037 & 0,80 & 1,00 & 0,80 & 1,10 & 7,10 & 1,30 & 12,00 & 1,70 & 37,50 & 2,50 & & & & & 40,20 & 4,32 & & & 3,80 & 2,90 & & \\
\hline AR-040 & & & & & 3,60 & 1,30 & 3,30 & 1,70 & 55,30 & 2,40 & 1,00 & 3,67 & & & 37,10 & 4,17 & & & & & & \\
\hline AR-060 & 2,30 & 2,10 & 1,10 & 1,10 & 3,50 & 1,30 & 6,30 & 1,70 & 49,6 & 2,50 & 1,50 & 3,64 & & & 36,00 & 4,20 & & & & & & \\
\hline AR-121 & 2,10 & 2,03 & 0,10 & 0,95 & 3,70 & 1,30 & 2,70 & 1,66 & 50,50 & 2,64 & 2,20 & 3,64 & & & 38,80 & 4,32 & & & & & & \\
\hline AR-130 & 0,70 & 1,44 & 0,30 & 0,94 & 3,80 & 1,32 & 5,30 & 1,65 & 51,20 & 2,60 & 1,90 & 3,65 & & & 33,90 & 4,29 & & & 2,70 & 2,05 & & \\
\hline AR-131 & 0,60 & 1,22 & 1,50 & 1,11 & & & 0,20 & 1,70 & 4,10 & 2,06 & 3,50 & 3,68 & & & 88,80 & 4,30 & & & 0,10 & 2,51 & 1,20 & 2,90 \\
\hline AR-135 & 2,40 & 2,06 & 2,00 & 1,12 & 3,80 & 1,31 & 3,00 & 1,71 & 52,40 & 2,66 & 2,80 & 3,65 & & & 31,50 & 4,28 & 2,10 & 5,18 & & & & \\
\hline AR-136 & 0,40 & 2,06 & 59,70 & 1,23 & & & 1,30 & 1,66 & 19,80 & 2,62 & & & & & 12,20 & 4,20 & & & & & & \\
\hline AR-137 & 2,00 & 2,06 & 0,70 & 1,13 & 3,60 & 1,32 & 4,10 & 1,66 & 56,80 & 2,64 & 2,20 & 3,64 & & & 30,80 & 4,29 & & & & & & \\
\hline AR-156 & 0,70 & 2,74 & 2,80 & 1,10 & & & 0,70 & 1,63 & 4,40 & 2,05 & 12,00 & 3,49 & & & 79,40 & 4,30 & & & & & & \\
\hline AR-163 & 1,80 & 2,08 & 0,60 & 1,13 & 2,90 & 1,34 & 2,50 & 1,70 & 49,90 & 2,64 & 1,10 & 3,68 & & & 41,20 & 4,31 & & & & & & \\
\hline AR-171 & 2,30 & 2,08 & 0,20 & 1,12 & 3,60 & 1,34 & 2,50 & 1,74 & 53,60 & 2,64 & 2,00 & 3,68 & & & 35,70 & 4,30 & & & & & & \\
\hline AR-180 & 2,00 & 2,08 & 0,70 & 1,12 & 4,00 & 1,34 & 2,40 & 1,74 & 57,20 & 2,68 & 1,90 & 3,68 & & & 31,80 & 4,30 & & & & & & \\
\hline AR-196 & 0,20 & 0,94 & 0,70 & 1,11 & 3,00 & 1,30 & 4,70 & 1,64 & 49,70 & 2,64 & 2,00 & 3,63 & & & 36,80 & 4,31 & & & 0,50 & 1,43 & 2,20 & 2,02 \\
\hline AR-199 & 0,90 & 1,20 & 1,20 & 1,10 & & & 0,20 & 1,67 & 4,50 & 2,02 & 3,60 & 3,64 & 87,60 & 4,34 & & & & & 0,10 & 2,44 & 1,60 & 2,72 \\
\hline AR-200 & 2,20 & 2,04 & & & 3,80 & 1,31 & 2,20 & 1,70 & 50,40 & 2,71 & 2,20 & 3,65 & 38,10 & 4,35 & & & 1,30 & 5,22 & & & & \\
\hline AR-201 & 1,70 & 2,03 & 0,40 & 1,10 & 2,90 & 1,31 & 1,80 & 1,70 & 51,00 & 2,70 & 2,30 & 3,66 & 40,00 & 4,36 & & & & & & & & \\
\hline AR-208 & 1,70 & 2,32 & 5,40 & 1,11 & & & & & 2,10 & 2,04 & 3,80 & 3,64 & 48,20 & 4,58 & 37,70 & 4,30 & & & & & & \\
\hline AR-209 & 0,30 & 0,94 & 1,70 & 1,10 & 3,30 & 1,30 & 6,40 & 1,65 & 49,00 & 2,60 & 2,40 & 3,62 & & & 33,50 & 4,26 & & & 0,70 & 1,44 & 2,70 & 2,04 \\
\hline AR-212 & 1,10 & 2,04 & 23,70 & 1,17 & & & 4,80 & 1,66 & 38,00 & 2,66 & 1,60 & 3,62 & & & 29,20 & 4,26 & & & & & & \\
\hline AR-213 & 0,30 & 0,94 & 0,80 & 1,22 & 2,10 & 1,31 & 5,60 & 1,64 & 49,40 & 2,67 & 1,90 & 3,64 & 36,50 & 4,34 & & & & & 0,80 & 1,12 & 0,60 & 1,44 \\
\hline AR-216 & & & 1,60 & 1,06 & 4,50 & 1,29 & 6,30 & 1,78 & 64,90 & 2,64 & 6,30 & 3,80 & & & 16,20 & 4,12 & & & & & & \\
\hline AR-217 & & & 1,40 & 1,06 & 4,40 & 1,29 & 6,30 & 1,76 & 65,10 & 2,65 & 7,20 & 3,76 & & & 14,60 & 4,10 & 0,90 & 5,28 & & & & \\
\hline AR-218 & 2,50 & 2,00 & & & 5,20 & 1,29 & 2,80 & 1,67 & 50,90 & 2,64 & 2,10 & 3,59 & & & 36,50 & 4,30 & & & & & & \\
\hline AR-219 & & & 1,30 & 1,06 & 4,40 & 1,29 & 6,40 & 1,77 & 65,30 & 2,64 & 6,10 & 3,77 & & & 16,40 & 4,11 & & & & & & \\
\hline AR-221 & 2,20 & 2,04 & & & 4,30 & 1,32 & 2,00 & 1,68 & 47,70 & 2,65 & 2,20 & 3,62 & & & 41,60 & 4,25 & & & & & & \\
\hline AR-234 & 1,70 & 2,04 & 0,30 & 1,12 & 3,30 & 1,31 & 1,90 & 1,69 & 54,80 & 2,63 & 2,00 & 3,61 & & & 35,90 & 4,25 & & & & & & \\
\hline AR-236 & 2,80 & 2,10 & 2,80 & 1,13 & 4,00 & 1,34 & 3,10 & 1,71 & 51,00 & 2,56 & 2,30 & 3,67 & & & 34,10 & 4,21 & & & & & & \\
\hline AR-237 & 0,50 & 1,12 & 0,70 & 1,24 & 2,50 & 1,34 & 1,90 & 1,70 & 46,70 & 2,56 & 2,30 & 3,69 & & & 42,80 & 4,26 & & & 2,60 & 2,09 & & \\
\hline AR-238 & 2,40 & 2,15 & 1,30 & 1,15 & 3,00 & 1,38 & 1,80 & 1,74 & 50,10 & 2,58 & 1,80 & 3,72 & & & 39,50 & 4,24 & & & & & & \\
\hline AR-239 & & & 0,40 & 1,15 & 3,20 & 1,37 & 2,40 & 1,72 & 56,70 & 2,56 & 1,90 & 3,71 & & & 35,40 & 4,22 & & & & & & \\
\hline AR-240 & & & 34,90 & 1,22 & & & 3,10 & 1,74 & 38,00 & 2,56 & 1,20 & 3,71 & & & 22,80 & 4,21 & & & & & & \\
\hline G-006 & 2,30 & 1,22 & 4,60 & 1,09 & 3,00 & 1,43 & 7,60 & 1,67 & 49,90 & 2,48 & & & & & 31,50 & 4,15 & 1,50 & 1,93 & & & & \\
\hline G-032 & 3,00 & 2,08 & & & 4,10 & 1,33 & 5,20 & 1,66 & 49,40 & 2,43 & 1,30 & 3,62 & & & 37,10 & 4,18 & & & & & & \\
\hline G-034 & & & 1,10 & 1,07 & 2,90 & 1,33 & 2,30 & 1,68 & 53,30 & 2,42 & 1,70 & 3,63 & & & 39,00 & 4,18 & & & & & & \\
\hline G-035 & & & 1,40 & 1,24 & 2,50 & 1,34 & 4,30 & 1,68 & 53,60 & 2,44 & 1,30 & 3,66 & & & 37,00 & 4,21 & & & & & & \\
\hline G-036 & & & & & 4,20 & 1,34 & 4,50 & 1,68 & 54,60 & 2,44 & 1,30 & 3,66 & & & 35,50 & 4,20 & & & & & & \\
\hline Média & 1,60 & & 4,77 & & 3,80 & & 3,70 & & 46,90 & & 2,62 & & 50,10 & & 35,40 & & 1,50 & & 1,41 & & 1,70 & \\
\hline DP & 0,90 & & 12,10 & & 1,00 & & 2,20 & & 16,67 & & 2,10 & & 21,50 & & 14,40 & & 0,50 & & 1,41 & & 0,80 & \\
\hline Min & & 0,90 & & 0,90 & & 1,30 & & 1,60 & & 2,00 & & 3,49 & & 4,34 & & 4,10 & & 1,93 & & 1,10 & & 1,40 \\
\hline Máx & & 2,70 & & 1,20 & & 1,40 & & 1,80 & & 2,70 & & 3,80 & & 4,58 & & 4,32 & & 5,28 & & 2,90 & & 2,90 \\
\hline
\end{tabular}


de PCR e análise dos fragmentos após digestão com a enzima EcoRI. Todas as amostras testadas apresentaram três fragmentos: dois que constituem o alelo normal, com 296pb e 268pb, que foi clivado pela enzima, e outro fragmento de $564 \mathrm{pb}$ resultante do alelo mutante. A mutação na primeira base da trinca, na posição 121 retira o sítio específico para essa enzima; dessa forma, não há o reconhecimento de nenhum local para digestão pela enzima EcoRI.

O seqüenciamento foi realizado em dez das amostras para confirmação da mutação.

Os casos com interações, como Hb D Los Angeles e talassemia beta e $\mathrm{Hb} \mathrm{S}$ e D Los Angeles foram confirmados com a utilização da metodologia PCR-ASO, que possui sensibilidade para discriminar 16 mutantes de talassemia beta e as hemoglobinas variantes $\mathrm{S}$ e $\mathrm{C}$.

Desse modo, dos 47 indivíduos analisados, 42 apresentaram o padrão heterozigoto para Hb D Los Angeles, dois indivíduos o padrão $\mathrm{Hb} S$ e D Los Angeles, dois indivíduos com o padrão $\mathrm{Hb} \mathrm{D}$ Los Angeles e talassemia beta e um indivíduo com $\mathrm{Hb} \mathrm{D}$ Los Angeles e Hb Lepore.

\section{Discussão}

A Hb D Los Angeles ou D Punjab foi primeiramente descrita por Itano, em 1951, em uma família residente em Los Angeles, descendente de ingleses e indianos; em 1962 sua estrutura química foi caracterizada como sendo uma substituição do ácido glutâmico por glutamina na globina beta. Apesar dessa variante possuir uma ampla distribuição mundial, seu maior reservatório encontrase no subcontinente indiano. Estima-se que 3\% da populaç̃o de Punjab, na Índia, seja portadora heterozigota dessa variante..$^{20,21} \mathrm{Na}$ América Latina, essa hemoglobina foi descrita no Brasil, Argentina, Cuba, Guadaloupe, Jamaica, Venezuela e México. ${ }^{4}$ Em nosso país, a Hb D Los Angeles é a terceira variante mais comum, após as $\mathrm{Hb} \mathrm{S}$ e Hb C. ${ }^{10}$

A eletroforese de hemoglobinas em acetato de celulose, pH alcalino é o método mais usado para a identificação de hemoglobinas; entretanto, sua sensibilidade é limitada, especialmente nos casos de co-migração de isoformas, como as hemoglobinas S, D, G e Korle-Bu, dificultando o diagnóstico adequado. As eletroforeses ácida e de cadeias globínicas podem auxiliar na diferenciação, porém, também apresentam limitações. Atra- vés da eletroforese em gel de ágar, pH ácido, podese diferenciar as $\mathrm{Hb} \mathrm{S}$ do tipo $\mathrm{D}$, uma vez que as $\mathrm{Hb}$ tipo $\mathrm{D}$ migram de forma semelhante à $\mathrm{Hb} \mathrm{A}$ neste $\mathrm{pH}$. As $\mathrm{Hb} \mathrm{G}$ e Korle-Bu apresentam o mesmo comportamento eletroforético da $\mathrm{Hb} \mathrm{D}$ Los Angeles nesses procedimentos eletroforéticos. Com a utilização da eletroforese de cadeias globínicas, pH alcalino, é possível a diferenciação das Hb D e $\mathrm{Hb} \mathrm{G}$, que é um mutante de cadeia alfa. As $\mathrm{Hb} \mathrm{D}$ $\mathrm{Hb}$ Korle-Bu poderão ser diferenciadas molecularmente, uma vez que apresentam os mesmos padrões de migração nos vários procedimentos eletroforéticos, incluindo a eletroforese de cadeias globínicas. Na cromatografia líquida de alta pressão (HPLC), a Hb Korle-Bu é eluída na janela de $\mathrm{Hb} \mathrm{D}$, porém com desvio da linha de base.

As amostras avaliadas apresentaram migração semelhante à $\mathrm{Hb} \mathrm{S}$ em pH alcalino, como $\mathrm{Hb} \mathrm{A}$ em pH ácido e uma banda na posição de mutante de cadeia beta na eletroforese de cadeias globínicas em $\mathrm{pH}$ alcalino, conforme relatos da literatura para este mutante. ${ }^{2,22}$ Entretanto, faz-se necessária a utilização de técnicas mais sensíveis para a correta caracterização dessa variante.

O uso do HPLC para análise de hemoglobinas tem aumentado nos últimos anos. ${ }^{23}$ Entretanto, o equipamento foi padronizado para a população norte-americana; desse modo, torna-se necessária a padronização dos resultados normais e das hemoglobinas variantes para a população brasileira, além do estabelecimento dos padrões para cada laboratório. Para a $\mathrm{Hb} \mathrm{A} 2$, a grande maioria das amostras analisadas apresentou valores abaixo da normalidade. Entretanto existem dados discordantes na literatura, que talvez possam ser explicados pelo uso de colunas ou sistemas de eluição diferentes. ${ }^{18}$ Com relação à hemoglobina $\mathrm{D}$, em nossos achados, foi encontrado o tempo de retenção médio de 4,24, com mínimo de 4,1 e máximo de 4,32, portanto, dentro dos limites estabelecidos pelo fabricante, que são: mínimo de 3,91 e máximo de 4,33 .

Fato que mereceu destaque foi o de algumas amostras eluídas na janela de $\mathrm{Hb} \mathrm{S}$. Nota-se, entretanto, que os valores do tempo de retenção dessas amostras foram de 4,34, 4,35 e 4,36. Esses valores encontram-se muito próximos ao valor máximo estabelecido pelos fabricantes para a janela de $\mathrm{Hb} \mathrm{D}$, que foi de 4,33 , e próximas ao valor mínimo para $\mathrm{Hb} \mathrm{S}$, que também é de 4,33. Se apenas o HPLC fosse utilizado para a caracterização dessa 
variante, provavelmente tais amostras seriam identificadas como Hb S. Além disso, os valores da porcentagem das amostras AR-131 (88,8\%) na janela de Hb D e AR-199 (87,6\%) na janela de Hb S poderiam mimetizar uma homozigose para as hemoglobinas citadas. Entretanto, nessas condições, os níveis de $\mathrm{Hb}$ D costumam estar próximos a 95\%. ${ }^{22}$ Os perfis eletroforéticos auxiliaram a elucidação destes casos, destacando-se a importância da utilização de metodologias clássicas aliadas a técnicas de maior sensibilidade, como HPLC, na avaliação de hemoglobinas do Brasil.

Após a amplificação por PCR e digestão enzimática com a endonuclease de restrição EcoRI, as amostras de DNA analisadas apresentaram os fragmentos correspondentes ao alelo mutante para $\mathrm{Hb} \mathrm{D}$ Los Angeles e normal. Esses achados confirmam a presença de $\mathrm{Hb} \mathrm{D}$ Los Angeles em todas as amostras e excluem definitivamente a homozigose das amostras AR-131 e AR-199.

A metodologia PCR-ASO foi utilizada para confirmação nos casos em que havia interação de $\mathrm{Hb} \mathrm{D}$ Los Angeles com outras variantes, como a $\mathrm{Hb} S$ ou talassemias, com exceção da amostra AR156. Assim, na amostra AR-131 foram confirmadas as mutacões CD-39 e CD6-A, e na amostra AR-199 a mutação CD-39 para talassemia beta; na amostra AR-208, a presença do alelo beta S, originando um duplo heterozigoto S/D Los Angeles. Para o indivíduo (S/D Los Angeles) G-108, a confirmação foi realizada através de seqüenciamento.

A Hb D-Los Angeles foi descrita tanto em heterozigose como em homozigose, assim como em combinação com Hb S ou talassemias alfa ou beta. ${ }^{4,22,24}$ Os indivíduos heterozigotos são assintomáticos; em homozigose podem apresentar diminuição da fragilidade osmótica, células em alvo e níveis de hemoglobina A2 normais, mas é uma situação rara.

A co-herança de $\mathrm{Hb} \mathrm{D}$ e talassemia beta é pouco descrita na literatura mundial. ${ }^{22}$ Os portadores de $\mathrm{Hb} \mathrm{D}$ e talassemia beta apresentam anemia hemolítica de leve a moderada. 4,6,22 Os indivíduos portadores da associação entre $\mathrm{Hb} S$ e D, chamada doença de $\mathrm{Hb} \mathrm{S} / \mathrm{D}$, podem apresentar anemia hemolítica de leve a severa e clínica similar aos pacientes com anemia falciforme. ${ }^{4,6}$ Embora a Hb D não sofra falcização, o fenótipo severo associado à doença de $\mathrm{Hb} \mathrm{S} / \mathrm{D}$ pode ser devido a um aumento na polimerização da $\mathrm{Hb}$ S, que é facilitado pela mutação no códon 121.,22

\section{Conclusões}

Cada metodologia utilizada para a identificação das variantes de hemoglobinas apresenta limitações. Desse modo, faz-se necessária a utilização de técnicas clássicas associadas a estudos moleculares para a identificação acurada dessas hemoglobinas anormais. Dependendo da região do país analisada podemos encontrar diferentes freqüências para determinadas hemoglobinopatias, uma vez que algumas delas estão relacionadas à origem européia ou africana da população fundadora. Os valores dessas freqüências não estão ainda bem estabelecidos no nosso país. Além disso, com o aumento na utilização do HPLC para o estudo das hemoglobinopatias, será possível estabelecer um parâmetro para a população brasileira das diferentes frações de hemoglobinas. O presente estudo poderá auxiliar na identificação da Hb D-Los Angeles, através dos resultados apresentados, além de auxiliar na elucidação de associações raras. O perfil para Hb D Los Angeles, pelas amostras avaliadas, mostrou fração na faixa de $\mathrm{Hb} \mathrm{S}$ em eletroforese $\mathrm{pH}$ alcalino, como $\mathrm{Hb} \mathrm{A}$ em eletroforese $\mathrm{pH}$ ácido e na posição de mutante de cadeia beta na eletroforese de cadeias globínicas em pH alcalino; a morfologia eritrocitária foi discreta, e a resistência osmótica, na maioria dos casos, negativa. Por HPLC, a fração de Hb D situa-se em uma janela de tempo de retenção que varia de 4,1 a 4,32 e com média percentual de $35,44 \%$, sendo a fração de $\mathrm{Hb}$ A2 diminuída na maioria dos casos.

\section{Abstract}

The most common $\mathrm{Hb}$ D variant, the $\mathrm{Hb}$ D-Los Angeles, also know as Hb D-Punjab, originates through a GAA $\rightarrow$ CAA change at the 121 codon of the $\beta$ globin gene; this mutation results in the replacement of glutamic acid for glutamine in the protein. It is the third most common hemoglobin variant in the Brazilian population. This variant has electrophoretic migration in alkalinepHssimilar to $\mathrm{Hb}$ Sand identical migration to hemoglobin $\mathrm{A}$ in acidic pHs. Thus, several techniques are necessary for its correct diagnosis. The purpose of this work was to relate the different laboratorial techniques and molecular analyses to determine the profile of $\mathrm{Hb}$ D LosAngeles in Brazil. Fortyseven individuals from the Brazilian population with $\mathrm{Hb}$ D Los Angeleswerestudied. Multiple electrophoresis in several experimental conditions were carried out, in addition to high performanceliquid chromatography 
(HPLC) and molecular analysis to confirm this mutation. Four compound heterozygotes were observed: 42 in dividuals heterozygous $\mathrm{Hb} A D$ Los Angeles, two with $\mathrm{Hb} S / D$ Los Angeles disease, two individuals with $\mathrm{Hb} \mathrm{D}$ Los Angeles and beta-thalassemia and one with $\mathrm{Hb}$ D Los Angeles and $\mathrm{Hb}$ Lepore. The heterozygous hemoglobin D LosAngelesisasymptomatic, even though itsassociation with other variants and thalassemiasmay present varying degrees of clinical manifestations. The results presented emphasize the significance of the association of different laboratorial techniques for $D$ Los Angeles diagnosis, and help to elucidate rare combinations. Rev. bras. hematol. hemoter. 2003;25 (3):161-168

Key words: Hemoglobin D Los Angeles; laboratorial diagn osis; hemoglobin opathies.

\section{Referências Bibliográficas}

1. Vella F, Lehmann H. Haemoglobin D Punjab (D Los Angeles). Journal of Medical Genetics 1974;11:341-348.

2. Politis-Tsegos C et al. Homozygous haemoglobin D Punjab. Journal of Medical Genetics 1975;12:269-274.

3. El-Kalla S, Mathews AR. Hb D Punjab in the United Arab Emirates. Hemoglobin 1997;21:369-375.

4. Perea FJ et al. $\mathrm{Hb} \mathrm{D}$ Los Angeles associated with $\mathrm{Hb} \mathrm{S}$ or $\beta$-thalassemia in four Mexican mestizo families. Hemoglobin 1999;23:231-237.

5. Leoneli GG. Hemoglobina D - Caracterização eletroforética e molecular. 2001. 107f. Dissertacão (Mestrado em Genética). Instituto de Biociências, Letras e Ciências Exatas - Unesp, São José do Rio Preto-SP.

6. Fodor FH, Eng CM. Molecular exclusion of haemoglobin S D disease by prenatal diagnosis. Prenatal Diagnosis 1999;19:58-60.

7. Worthington $\mathrm{S}$, Lehmann $\mathrm{H}$. The first observation of $\mathrm{Hb}$ D Punjab $\beta 0$ thalassaemia in a English family with 22 cases of unsuspected $\beta 0$ thalassaemia minor among its members. Journal of Medical Genetics 1985;22:377-381.

8. Schnee J et al. Hb D Los Angeles (D Punjab) and Hb Presbyterian: analysis of the defect at the DNA level. Human Genetics 1990;84:365-367.

9. Silvestroni E, Bianco I. Screening for microcytemia in Italy: analysis of data collected in the past 30 years. Am J Hum Genet 1975;27:198-212.

10. Bonini-Domingos CR. Prevenção das hemoglobinopatias no Brasil - Diversidade Genética e Metodologia Laboratorial. 1993. 144f. Tese (Doutorado em Ciências) - Instituto de Biociências, Letras e Ciência Exatas, Univ. Estadual Paulista - Unesp, São José do Rio Preto-SP.

11. Marengo-Rowe AJ. Rapid electrophoresis and quantification of haemoglobin on cellulose acetate. J Clin Path 1965;18:790-792.
12. Vella F. Acid agar gel electrophoresis of human hemoglobin. Am J Clin Path 1968;49(3):440-442.

13. Schneider RG. Differentiation of electrophoretically hemoglobins - such as S, D ou G and P or $\mathrm{A}_{2}, \mathrm{C}$, $\mathrm{E}$ and $\mathrm{O}-$ by electrophoresis of the globin chains. Clin Chem 1974;20:1.111-1.115.

14. Naoum PC. Eletroforese - Técnicas e Diagnósticos. $2^{2}$ edição. Santos Livraria Editora, 1999. 154 p.

15. Pena SDJ et al. DNA bioprints: simple non-isotopic DNA fingerprints with biotinnylated probes. Electrophoresis 1991;121:146-152.

16. Saiki RK et al. Primer-directed enzymatic amplification of DNA with a thermostable DNA polymerase. Science 1988;230:487-491.

17. Sanger F, Nicklen S, Coulson AR. DNA sequencing with chain - terminating inhibitors. Proc Natl Acad Sci 1977 74:5.463-5.467.

18. Huisman THJ Combinations of $\beta$ chain abnormal hemoglobins with each other or with $\beta$-thalassemia determinants with known mutations: influence on phenotype. Clinical Chemistry 1997;43:1.850-1.856.

19. Dash $\mathrm{S}$. Hb A2 in subjects with $\mathrm{Hb} \mathrm{D}$. Clinical Chemistry 1998;44:2.381-2.382.

20. Zeng $\mathrm{Y}$ et al. Identification of $\mathrm{Hb}$ D-Punjab gene application of DNA amplification in the study of abnormal hemoglobins. Am J Hum Genet 1989;44: 886-889.

21. Fioretti $G$ et al. DNA polymorphisms associated with $\mathrm{Hb}$ D Los Angeles [b 121 (GH4)GLU $\rightarrow$ GLN] in Southern Italy. Hemoglobin 1993;17:9-17.

22. Ahmed $\mathrm{M}$ et al. The $\beta$-globin genotype E121Q/W15X $(\mathrm{cd} 121 \mathrm{GAA} \rightarrow \mathrm{CAA} / \mathrm{cd} 15 \mathrm{TGG} \rightarrow \mathrm{TGA})$ underlines $\mathrm{HbD}$ $\beta$-(0) thalassaemia marked by domination of haemoglobin D. Ann Hematol 2001;80:629-633.

23. Riou J et al. Cation-exchange HPLC evaluated for presumptive identification of hemoglobin variants Clinical Chemistry 1997;43:34-39.

24. Ozsoylu S. Homozygous hemoglobin D Punjab. Acta Haemat 1970;43:353-359.

Avaliação: Editor e dois revisores externos

Conflito de interesse: não declarado

Recebido: 08/01/2003

Aceito a pós modificações: 28/05/2003 